\title{
Effectiveness of noninvasive ventilation in acute heart failure edema secondary to acute coronary syndrome
}

\author{
J Canovas*, A Lopez, DO Torres, A Burruezo, L Capilla, A Carrillo \\ From ESICM LIVES 2015 \\ Berlin, Germany. 3-7 October 2015
}

\section{Introduction}

The noninvasive ventilation (NIV) has been used successfully in acute respiratory failure (ARF) due to heart failure. However, patients with acute coronary syndrome have worse outcome than other ethologies of heart failure.

\section{Objetives}

Primary objective: To analyze the effectiveness of NIV in patients with ARF due to acute heart failure due to acute coronary syndrome (AHF-ACS) or other causes (AHFNACS). The secondary objective is to analyze the risk factors related to failure of NIV in these patients.

\section{Methods}

Prospective study, for 16 years, in patients admitted to the ICU with ARF due to hear failure requiring treatment with NIV. The criteria for initiation of NIV were respiratory rate $>30, \mathrm{PaO} 2 / \mathrm{FiO} 2<250$ or accessory muscles respiratory activity. The diagnosis of ACS was conducted by the European Society of Cardiology / American College of Cardiology criteria. Success of NIV was defined as avoiding intubation and be discharged alive plant. The results are expressed as mean \pm standard deviation and absolute and relative frequencies. Comparisons between variables using Student $\mathrm{T}$ and Pearson $\mathrm{Chi}^{2}$. Multivariate logistic regression analysis.

\section{Results}

During the study period, 1088 patients were admitted with AHF who required NIV, 453 (41.6\%) with ACS. BiPAP mode was used in 993 patients $(91.3 \%)$ and the rest CPAP. Do not intubate order in 258 patients (23.7\%): Age at AHF-ACS group was $75 \pm 9$ and AHF-NACS $74 \pm 10$ $(\mathrm{p}=0.235)$ and SAPS II: $43 \pm 13$ and $43 \pm 12$, respectively $(\mathrm{p}=0.933)$. Respiratory parameters in patients and AHF AHF-ACS-NACS show: respiratory rate $37 \pm 5$ and $36 \pm 5$ (p: 0.187), pH: $7.35 \pm 0.12$ and $7.36 \pm 0.12(\mathrm{p}: 0.175)$ and $\mathrm{PaO} 2 / \mathrm{FiO} 2: 127 \pm 32$ and $130 \pm 32(\mathrm{p}=0.101)$. LVEF was $32 \pm 9$ and $40 \pm 13$, respectively. Arterial hypotension at the time of initiation of NIV was $26.9 \%$ in AHF-ACS and $14.5 \%$ in AHF-NACS $(\mathrm{p}<0.001)$. NIV success was obtained in $320(70.6 \%)$ and $539(84.9 \%)(\mathrm{p}<0.001)$ and hospital mortality in $342(75.5 \%)$ and 560 (88.2\%), respectively $(\mathrm{p}<0.001)$. By multivariate analysis, predictors for NIV failure were: ACS (OR: 3.05; 95\% -CI: 1.91-4.88; p < 0.001), SAPS II (OR: 1.05; 95\% -CI: 1.03-1.07; p < 0.001), COPD (OR: 0.385 95\% -CI: 0.19 to 0.78 ; p:0.008), respiratory rate 1 hour-NIV (OR: 1.09; 95\% -CI: 1.04-1.14;p < 0.001), $\mathrm{PaO} 2$ / FiO2 1 hour-NIV (OR: 0.98; 95\% -CI: 0.98 -0.99; p:0.008), NIV-related complication (OR: 4.98; 95\% -CI: 3.04-8.16; $<$ 0.001), and SOFA maximum (OR: 1.54; 95\% -CI: 1.43-1.67; $<0.001$ ).

\section{Conclusions}

Patients with ACS as a cause of AHF have a greater number of failures of NIV, leading to a worse prognosis and causing increased mortality.

Published: 1 October 2015

doi:10.1186/2197-425X-3-S1-A170

Cite this article as: Canovas et al:: Effectiveness of noninvasive

ventilation in acute heart failure edema secondary to acute coronary syndrome. Intensive Care Medicine Experimental 2015 3(Suppl 1):A170. 